\title{
Bioaerosol Contribution to Atmospheric Particulate Matter in Indoor University Environments
}

\author{
Francesca Marcovecchio (D) and Cinzia Perrino *(D) \\ C.N.R. Institute of Atmospheric Pollution Research, National Research Council of Italy, Monterotondo St., \\ 00015 Rome, Italy; marcovecchio@iia.cnr.it \\ * Correspondence: perrino@iia.cnr.it
}

check for

updates

Citation: Marcovecchio, F.; Perrino,

C. Bioaerosol Contribution to

Atmospheric Particulate Matter in

Indoor University Environments.

Sustainability 2021, 13, 1149.

https://doi.org/10.3390/su13031149

Received: 1 December 2020

Accepted: 19 January 2021

Published: 22 January 2021

Publisher's Note: MDPI stays neutral with regard to jurisdictional claims in published maps and institutional affiliations.

Copyright: (c) 2021 by the authors. Licensee MDPI, Basel, Switzerland. This article is an open access article distributed under the terms and conditions of the Creative Commons Attribution (CC BY) license (https:// creativecommons.org/licenses/by/ $4.0 /)$.

\begin{abstract}
Within the framework of the project "Integrated Evaluation of Indoor Particulate Exposure", we carried out a 4-week field study to determine indoor bioaerosol, and its contribution to particulate matter $(\mathrm{PM})_{10}$ and organic matter. The study was carried out in university classrooms, where most of the common indoor sources of atmospheric particles are missing. Bioaerosol was determined by a method based on propidium iodide staining, observation by fluorescence microscopy, and image analysis. Indoor bioaerosol concentrations were compared with outdoor values, which were determined simultaneously. The samplings periods were scheduled to divide weekday hours, when the students were inside, from night-time hours and weekends. Very high bioaerosol concentrations were detected inside the classrooms with respect to outdoor values. The mean difference was $49 \mu \mathrm{g} / \mathrm{m}^{3}$ when the students were inside, $5.4 \mu \mathrm{g} / \mathrm{m}^{3}$ during the night, and it became negative during the weekends. Indoor-to-outdoor ratios were 6.0, 4.2, and 0.7, respectively. Bioaerosol contributed $26 \%$ to organics and $10 \%$ to $\mathrm{PM}_{10}$. In indoor samples collected during the day, the microscope images showed numerous skin fragments, which were mostly responsible for the increase in the bioaerosol mass. People's presence proved to be responsible for a significant increase in bioaerosol concentration in crowded indoor environments.
\end{abstract}

Keywords: fluorescence microscopy; air quality; infiltration; organic matter; biological debris; indoor pollution

\section{Introduction}

Among the main objectives of the project "Integrated Evaluation of Indoor Particulate Exposure" (VIEPI) there was the chemical characterization of particulate matter (PM) suspended in the atmosphere of indoor environments, and the evaluation of its infiltration dynamics [1]. One of the PM components taken into account by this objective was the fraction of organic particulate matter attributable to bioaerosol.

Primary biological aerosol particles, or bioaerosol, include all types of particles derived from biological organisms, namely viruses, bacteria, fungi and fungal spores, pollen, and fragments of animal and plant organisms [2]. Bioaerosol constitutes a fraction of atmospheric particulate matter still poorly investigated from an environmental point of view, as these measurements have long been mainly carried out by cultivation methods, and aimed at assessing species potentially dangerous to human health. Cultivation methods, however, neglect most of the environmental bioaerosols, which are non-viable or non-culturable. Different approaches, based on the use of biomarkers, for the determination of specific classes of bioaerosol components (e.g., phytosterols and chlorophyll for vegetable cells, dipicolinic acid for bacterial spore, ergosterol for fungal components, cellulose for plant debris) have gradually been added to this technique [3-7], as well as new molecular biology techniques, such as quantitative polymerase chain reaction (qPCR) and metagenomics approaches, among which are next generation sequencing (NGS) platforms [8,9]. Methods providing information about bioaerosol as a whole (that is, encompassing the wide variety 
of biological particles contained in a PM sample and not just a single bioaerosol category) have been developed only recently. These include real-time fluorescence monitors, such as the ultraviolet aerodynamic particles sizer and the waveband integrated bioaerosol sensor [10-12], and techniques based on PM sampling on a filter membrane, and subsequent selective staining and observation of the particles of biological origin $[13,14]$. In particular, a method based on staining with propidium iodide, light microscopy analysis, processing of results by specific software, and calculating the mass of total bioaerosol proved efficient in determining the overall bioaerosol content in PM [13].

There is an extensive scientific literature about PM chemical composition, including bioaerosol, in crowded indoor environments, such as residential houses, hospitals, working sites, and aircraft ([15-18], among others). However, only a few studies were specifically focused on the air quality of schools or academic environments [19-28], and only a few of these considered the bioaerosol and quantified its concentration. These studies were generally limited to some bio-components, such as viable fungi or bacteria, representing a fraction of only about $1 \%$ of total bioaerosol mass [29-38].

Instead, knowledge of the overall bioaerosol contribution to the mass concentration of PM in indoor sites is an essential environmental target, as in these sites the presence of people causes the release of typical bio-components (e.g., leather flakes), constituting a source that adds to the infiltration of bioaerosol from outside $[39,40]$. In the environments where many people stay for a long time, such as university classrooms, this source may become quantitatively important and essential for apportioning PM sources.

Moreover, bioaerosol in confined sites may cause health problems, such as allergies, irritation, infectious diseases, and inflammation [34,41]. In particular, the atmospheric bioaerosol has been indicated as one of the possible causes of sick building syndrome, characterized by headache, inability to concentrate, shortness of breath, sleepiness, and sluggishness [42]. However, the health impacts of atmospheric bioparticles are still an unexplored area of study that needs many more experimental observations.

An examination of the studies addressing bioaerosol detection in academic environments, still indicates a gap of knowledge about the quantitative detection of all bioaerosol categories and their contribution to PM concentration, as well as the link between atmospheric bioaerosol and the presence of people.

Within the VIEPI project, the mass concentration of bioaerosol, its contribution to $\mathrm{PM}_{10}$, and to its organic fraction were determined during a 4-week campaign. The study was carried out in three university classrooms, ranging from a computer room typically occupied by 30-40 people, to a lecture hall that can accommodate up to 300 students. In this paper, we report the results obtained from the measurement of bioaerosol in these environments, and discuss our findings in terms of particle characteristics, indoor/outdoor ratio, and the role played by people's presence.

\section{Experimental}

\subsection{Study Design}

The measurements were carried out at the Physics Department of the Sapienza University, located within the university area, in Rome's urban area (Google coordinates: $\left.41^{\circ} 54^{\prime} 06.16^{\prime \prime} \mathrm{N} ; 12^{\circ} 30^{\prime} 57.85^{\prime \prime} \mathrm{E}\right)$. Three rooms were chosen: the lecture hall ( $\left.\mathrm{LH}\right)$, located on the ground floor, and with a capacity of 300 seats (about $1150 \mathrm{~m}^{3}$ in volume); a classroom (A4), having dimensions identical to half of the lecture hall, and located just above it, able to accommodate up to 130 students (about $570 \mathrm{~m}^{3}$ ); and a Computer Room (CR), located at the same level of A4, and equipped with 42 seats (about $450 \mathrm{~m}^{3}$ ). The outdoor site was located on the ground floor, immediately outside the building, in a position overlooked by the three classrooms. The university's location inside the city, a picture of the building, and a scheme of the sampling sites are shown in Figure 1. 

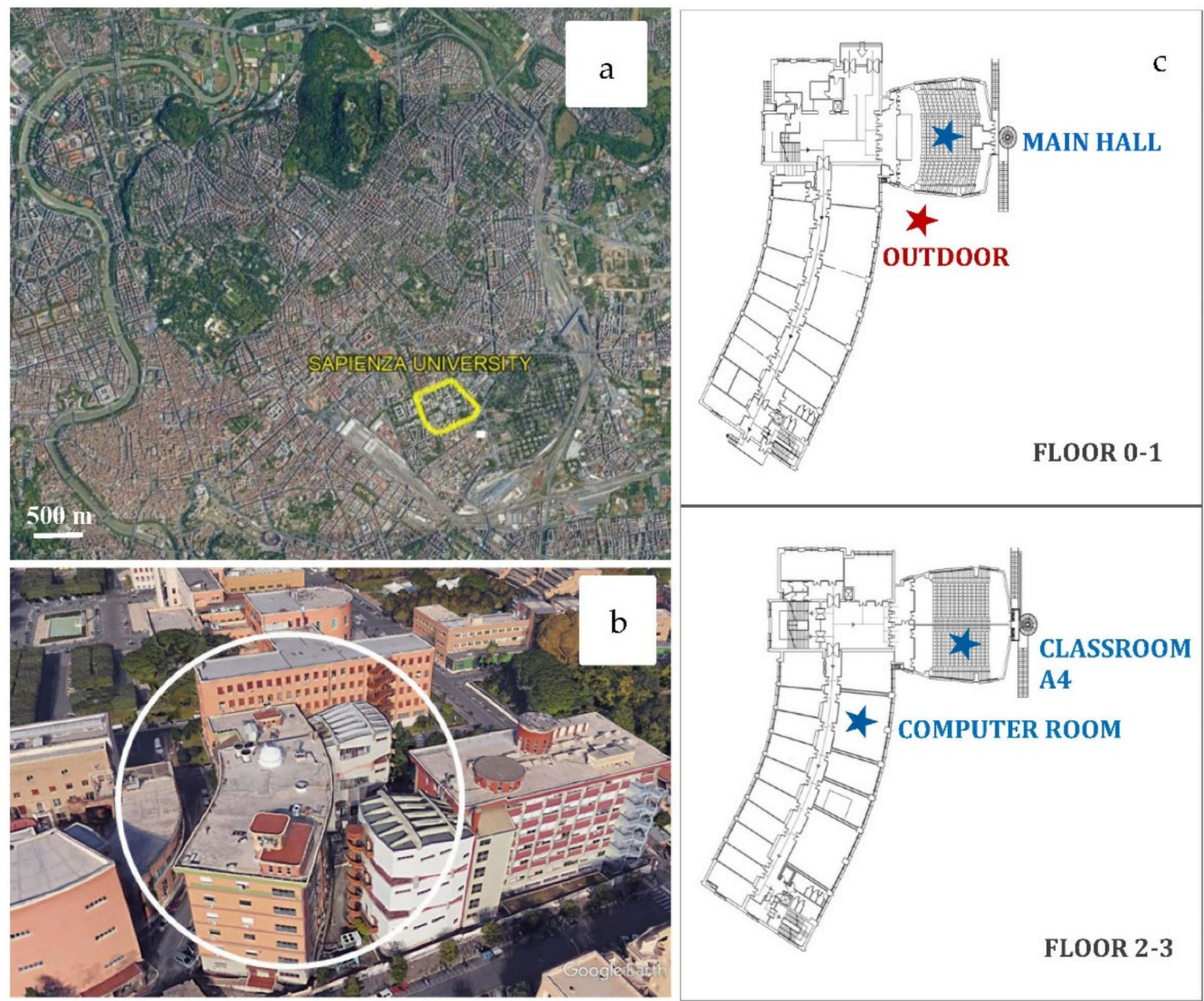

Figure 1. Area of the Sapienza University in the city of Rome (a), Physics Department building (b), and location of the sampling points (c).

The three rooms were naturally ventilated and equipped with hot-water radiators as heating appliances, in operation during the cold season. The classrooms were cleaned every working day before the lessons, during the time slot 6:00-8:00 a.m. Class periods were from 9:00 a.m. to 6:00 p.m. at A4 and CR, and from 8:00 a.m. to 7:00 p.m. at LH. The exact number of students attending each class could not be counted, but we could estimate that A4 and CR were, on average, fully occupied (about 130 and 42 students, respectively), while at LH the occupancy rate was more variable. In general, each class lasted for two hours, and there was a turnover of students between classes. Windows were generally opened for a few minutes at the end of each class.

Sampling was carried out simultaneously at all four sites during the winter of 2017, from 6 November to 3 December. The bioaerosol was determined from samples taken in A4 during the whole period, and on samples taken at all four sites during the week 13-19 November.

Sampling periods were scheduled to separate the hours when students were inside the room (day-time, 09:00 to 18:00 on weekdays, hereafter: day) from night-time hours (18:00 to 09:00 on weekdays, hereafter: night), and weekends (from Saturdays at 09:00 to Mondays at 09:00). Samplings dedicated to the determination of bioaerosol and those dedicated to the complete chemical analysis of PM (not reported in this paper) were carried out simultaneously. Sampling periods on Monday-Tuesday and Wednesday-Friday were combined to obtain PM amounts suitable for the different analytical techniques to be applied. As a final result, five samples were collected during each week: Mon-Tue day; Mon-Tue night; Wen-Fri day; Wen-Fri night; and weekend.

\subsection{Equipment}

PM was collected using very quiet samplers $(<35 \mathrm{~dB})$ specifically developed to operate in indoor environments without disturbing ongoing activities (Silent Sampler, FAI Instru- 
ments, Fonte Nuova, Rome, Italy). This feature is essential in very quiet environments, such as university classes during teaching activity. The same samplers, placed in a dedicated housing, were also used outdoors. The samplers operated at a flow rate of $10 \mathrm{~L} \mathrm{~min}^{-1}$ on filter membranes $47 \mathrm{~mm}$ in diameter. Each sampler was equipped with an automatic system able to work sequentially on four sampling lines, each one fit with a $\mathrm{PM}_{10}$ impactor. For outdoor samplings, the impactors were provided with a cap to protect the inlet from wind and rain. In each sampling site, we placed three samplers equipped, respectively, with Teflon (TEFLO, $47 \mathrm{~mm}, 2.0 \mu \mathrm{m}$ pore size, PALL Italia, Buccinasco, Italy), quartz (TISSUQUARTZ 2500QAT, $47 \mathrm{~mm}$, PALL Italia), and polycarbonate filters, the latter dedicated to bioaerosol measurements (polycarbonate filters, $0.8 \mu \mathrm{m}$ pore size, MILLIPORE, Merck Life Science, Milano, Italy).

The analyses were performed employing an epifluorescence microscope (Zeiss Imager M1m, Carl Zeiss Inc., Thornwood, NJ, USA) fit with a $100 \times$ N-ACHROPLAN oil objective and an AXIOCAM high-resolution camera, which allowed a total magnification of $1000 \times$. Image processing was performed using ImageJ software (NIH ImageJ software, National Institute of Health, Bethesda, MD, USA).

\subsection{Analysis}

The determination of bioaerosol was performed by applying the method developed and validated by Perrino and Marcovecchio [13]. Briefly, the samples were marked with a $1 \%$ solution of propidium iodide, a fluorochrome that binds to the nucleotide pair of guanine and cytosine in DNAs and RNAs, making the particles of biological origin fluorescent. For each sample, we observed 30 fields under the microscope. In the images, the particles of biological origin showed a red fluorescence on a black background. The images were processed to separate the RGB component into three channels (red, green, and blue). Those produced by the amplification of the red channel were used to generate a black and white, bi-level image, where bioparticles appear in black. The background of the image, containing all the other particles, is white. From this image, the software returns information about the circularity and size (length of the major and minor axes of the best-fitting ellipse, perimeter, area) of each particle. The volume of each particle was calculated considering each of them as an ellipsoid having the third axis equal to the minor axis. The mass was calculated by multiplying the particle volume by a density value of $1.1 \mathrm{~g} \mathrm{~cm}^{-3}$, estimated considering that particles of biological origin contain about $70 \%$ water, and that the remaining 30\% consists of protein material (density: $1.3 \mathrm{~g} \mathrm{~cm}^{-3}$ ). The size of the smallest detectable particle was $0.4 \mu \mathrm{m}$ [13]; the relative repeatability of the method is $16 \%$ for outdoor samples and $11 \%$ for indoor samples $[13,40]$; the overall uncertainty of the method is estimated to be in the range $20-25 \%$.

The method was applied as such to outdoor samples. For analyzing indoor samples, it was slightly modified to make it more suitable for observing corneocytes, particles produced from the epidermis's desquamation. Corneocytes are irregularly shaped, very large particles that often appear partially or entirely folded. The average value of the major diameter of the skin flakes in our indoor samples was $30 \pm 10 \mu \mathrm{m}$ (calculated over 431 bioparticles). Their average thickness, obtained from measurements carried out using high-resolution scanning electron microscopy, was about $0.8 \mu \mathrm{m}$ (FEI Quanta 400 SEM of the Research Center on Nanotechnology Applied to Engineering at the Sapienza University) (Figure 2). Despite their large size, the flattened shape and small density of these particles make their aerodynamic diameter small enough to pass through the inertial impactor inside the $\mathrm{PM}_{10}$ sampling head, and thus be considered $\mathrm{PM}_{10}$. It is plausible that even larger particles were suspended in the atmosphere, as the typical dimensions of skin scales are about $30 \times 40 \mu \mathrm{m}$ [43]. However, we have no information about the fraction of the total released bioparticles that were not collected by our $\mathrm{PM}_{10}$ impactor. 


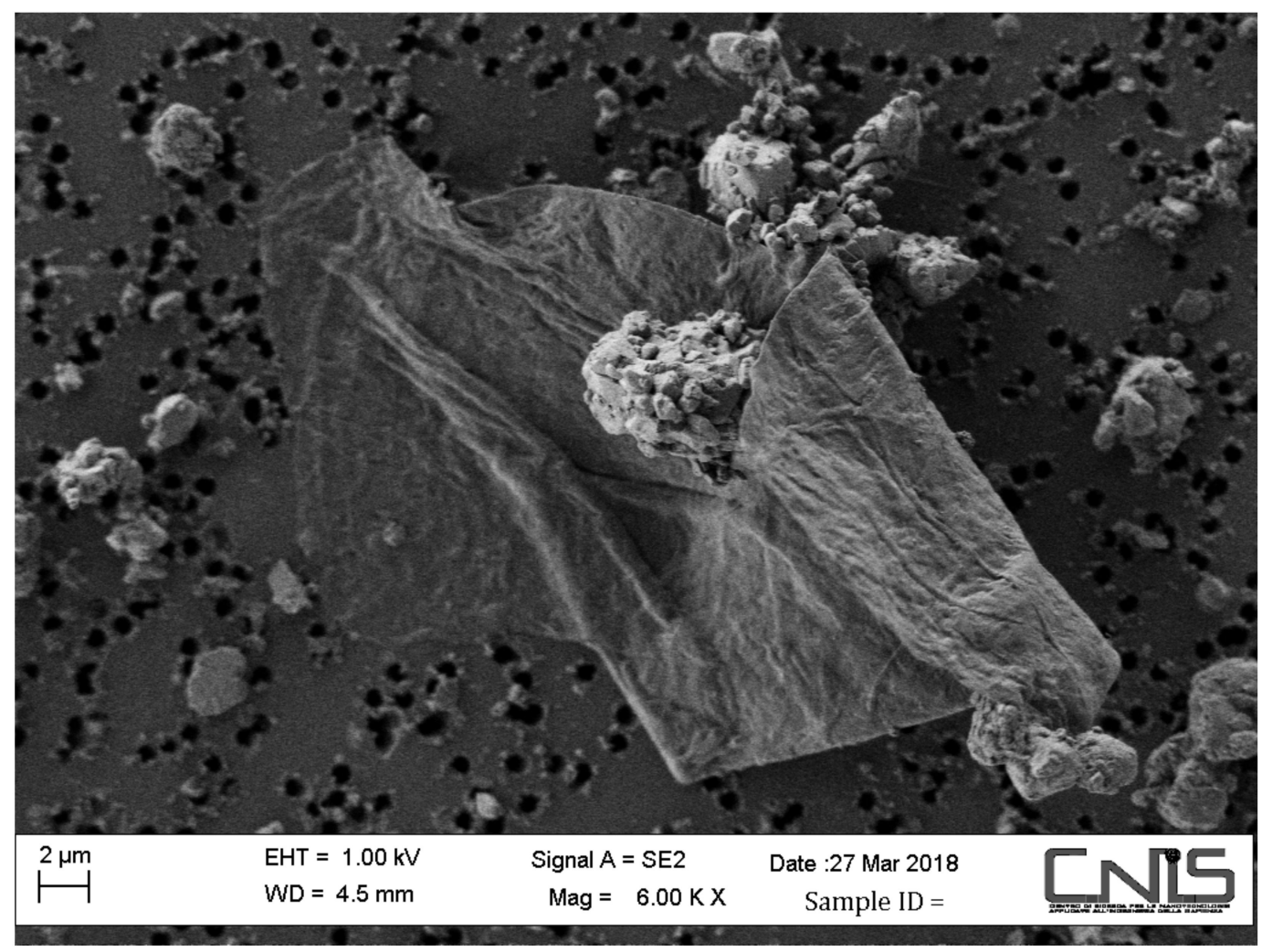

Figure 2. SEM image of a skin flake surrounded by soil components. The photo was taken by the CNIS (Research Center on Nanotechnology Applied to Engineering) of the Sapienza University of Rome.

Due to the characteristic shape of these particles, the procedure for estimating bioparticles mass was modified as follows: visual identification of skin flakes based on their size and appearance; calculation of their volume considering the area provided by the software and the thickness of $0.8 \mu \mathrm{m}$; and evaluation of the folding, which was taken into account by multiplying the volume obtained by 1.5 in the case of partially folded particles, or by 2 in the case of entirely folded particles [40].

PM mass was determined gravimetrically on Teflon membranes using an automatic balance with a sensitivity of $1 \mu \mathrm{g}$ (Sartorius mod. ME5, Sartorius, Germany). Before each weighing cycle, the filters were kept at $20^{\circ} \mathrm{C}$ and $50 \%$ R.H. for $48 \mathrm{~h}$. Teflon filters were also used to measure the inorganic chemical components of PM (results not reported in this paper).

Organic carbon (OC) determination was carried out on quartz filters by thermo-optical analysis, applying the NIOSH-QUARTZ thermal protocol (OCEC Carbon Aerosol Analyzer, Sunset Laboratory, Tigard, OR, USA). To estimate the organic matter (OM), it is necessary to multiply the $\mathrm{OC}$ value by a conversion factor, $\alpha$, that considers non- $\mathrm{C}$ atoms. The value of $\alpha$, that is the average molecular weight per carbon weight, depends on the composition of the organic material and its ageing by oxidation [44]. In the case of the outdoor site, which is located in an urban area but not directly exposed to traffic emissions, $\alpha$ was set to 1.8 [45]. For indoor sites, where the typical composition of the organic fraction is very different from outdoor air, and still mostly unknown, we applied the value $\alpha=1.4$ [46]. In all cases, this multiplication factor also considers possible negative or positive artefacts, due to the interaction of the sampled particles and the filter matrix with the organic vapors in the atmosphere.

\section{Results and Discussion}

Figure 3 shows the comparison of $\mathrm{PM}_{10}$ concentration measured inside classroom A4 with the concentration simultaneously measured outdoors. During the day, indoor concentrations were much higher than the corresponding outdoor values. These differences, 
$49 \mu \mathrm{g} / \mathrm{m}^{3}$ as a mean value, significantly reduced at night $\left(5.4 \mu \mathrm{g} / \mathrm{m}^{3}\right)$, and became negative during the weekend $\left(-6.1 \mu \mathrm{g} / \mathrm{m}^{3}\right)$. These results highlight the presence of important indoor sources of PM, which add to the infiltration from outside, and indicate that these sources were active during the daytime hours of weekdays.

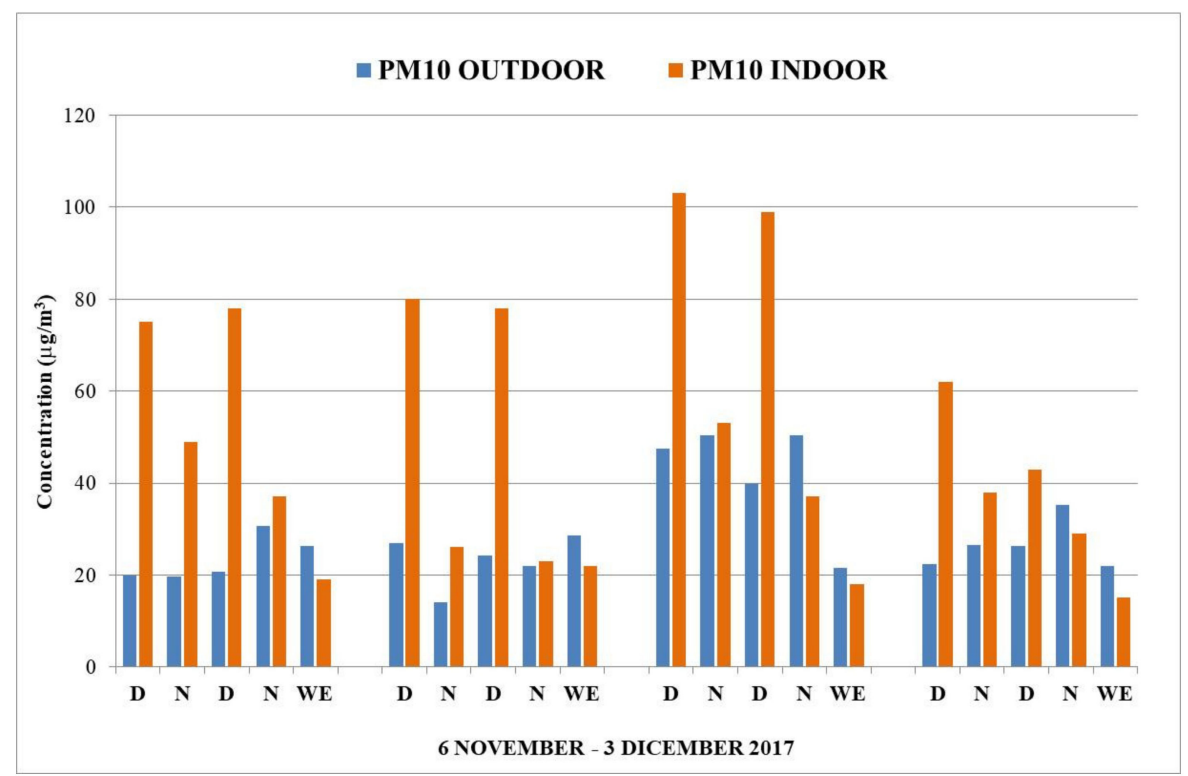

Figure 3. Comparison of outdoor and indoor concentration of particulate matter $\left(\mathrm{PM}_{10}\right)$ during the days (D), nights (N), and weekends (WE) of the study period in classroom A4. Sampling periods on Monday-Tuesday and Wednesday-Friday of each week have been combined.

University and school classrooms are particularly interesting because in these environments some of the typical indoor sources of PM are missing: cooking activities, biomass heating, cigarette smoke, textiles abrasion, use of electric appliances, body care products, and burning candles. In the classrooms considered in this study, smoking was forbidden, heating was made up of hot-water radiators, and furniture was limited to wooden and plastic desks, in use for several decades. Therefore, the source that may be responsible for the increase in PM concentration during day hours may be identified as students and teachers. The main mechanisms by which people are responsible for increasing indoor PM concentration are: the introduction from outside of particles, mainly coming from the soil; the release of biological particles; and the re-suspension, caused by their movements, of particles already deposited on the ground and surfaces. The complete chemical characterization of $\mathrm{PM}_{10}$ collected in the classrooms and outdoors has confirmed that the observed indoor increase was mainly due to both soil components and organics [1]. Considering that the classrooms were cleaned every day before the start of the lessons, we can also assume that the observed increase in $\mathrm{PM}_{10}$ concentration was due to actions occurring during the daytime periods, that is when people were inside the building, and that these actions also influenced the subsequent nights/weekends.

Bioaerosol concentration determined in A4 during the study period is shown in Figure 4a. In the same figure, the data are compared with the indoor concentration of OM and $\mathrm{PM}_{10}$ (panel b). Individual data are reported in Supplementary Materials, Table S1. It can be observed that all concentrations had a similar trend over the four weeks; as already observed for $\mathrm{PM}_{10}$, concentrations were high during the day, decreased during the night, and reached a minimum over the weekend. For bioaerosol, the average concentrations were $6.8 \mu \mathrm{g} / \mathrm{m}^{3}, 3.5 \mu \mathrm{g} / \mathrm{m}^{3}$, and $1.8 \mu \mathrm{g} / \mathrm{m}^{3}$ during the day, night, and weekends, respectively. 


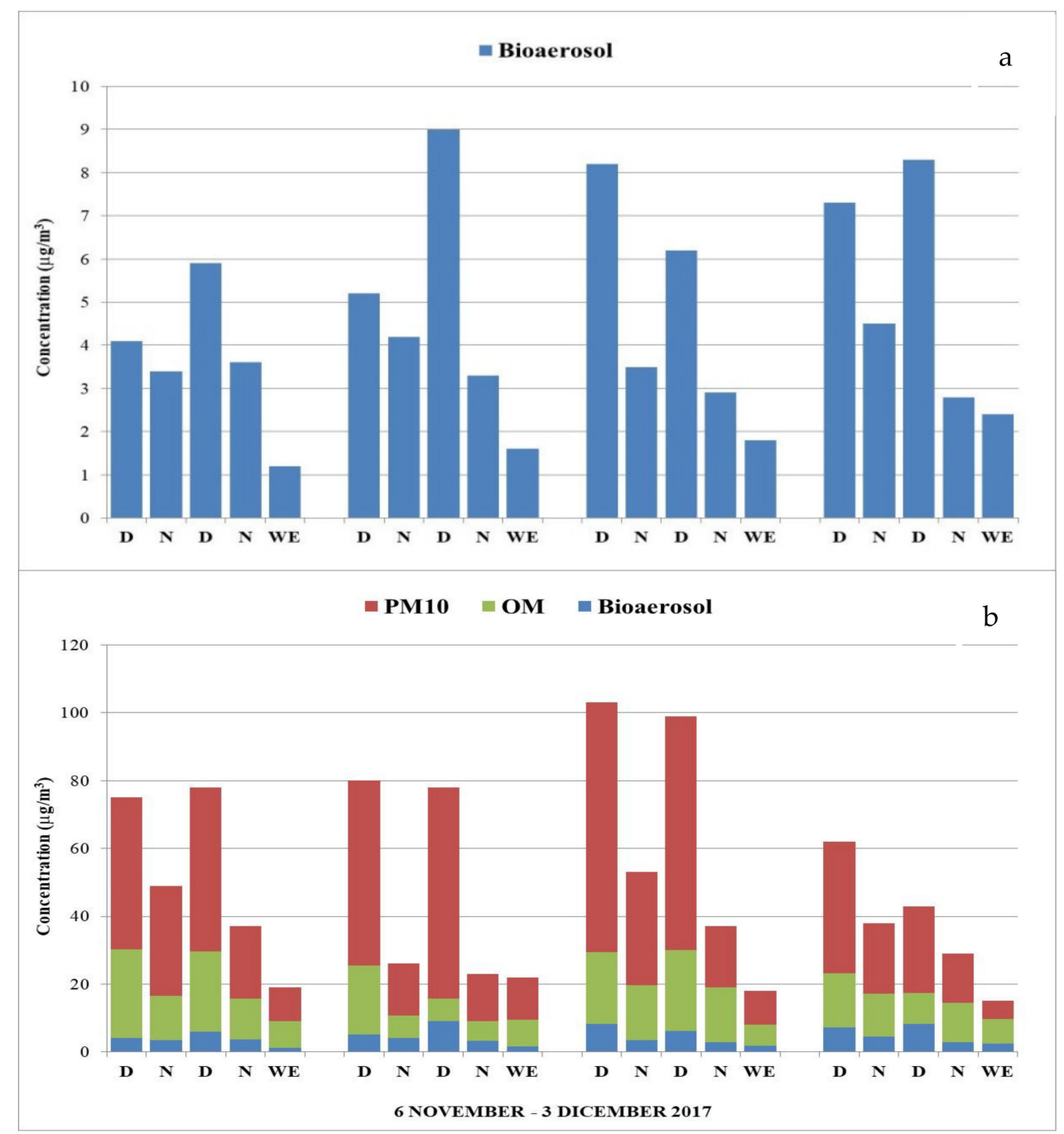

Figure 4. Bioaerosol concentration (a) and comparison with organic matter (OM) and $\mathrm{PM}_{10}(\mathbf{b})$ during the days (D), nights $(\mathrm{N})$, and weekends (WE) of the study period in classroom A4. Sampling periods on Monday-Tuesday and WednesdayFriday of each week were combined.

The existence of an important source of atmospheric PM due to people's presence was confirmed by visual observation of the bioaerosol in the microscopy images. Figure 5 shows, from top to bottom, the images referring to A4 during the day and night of 2728 November (Monday-Tuesday) and the weekend 2-3 December. The images show a different number of bioaerosol particles in the three samples, and numerous skin fragments (large and irregularly shaped) in the sample collected during the day. Due to their particular shape and density, these particles tended to sediment very slowly, and were still present, albeit to a lesser extent, in the samples collected during the night, while they were generally absent in the samples taken during the weekend.

Bioaerosol constituted a substantial mass fraction of PM; its contribution was about a quarter of the $\mathrm{OM}$ mass (on average, $26 \%$ ) and $10 \%$ of $\mathrm{PM}_{10}$. While bioaerosol contribution to $\mathrm{PM}_{10}$ had no significant time variations, its contribution to $\mathrm{OM}$ was, on average, $30 \%$ during the day, $25 \%$ at night, and $19 \%$ at weekends. These results can be explained considering that organic species other than bioaerosol are predominantly in the fine fraction of PM; consequently, their ability to infiltrate through the building envelope is higher. Since organic outdoor particles do not show significant time variations, the fraction that infiltrates inside the classroom influences night and weekend samples to a greater extent. 

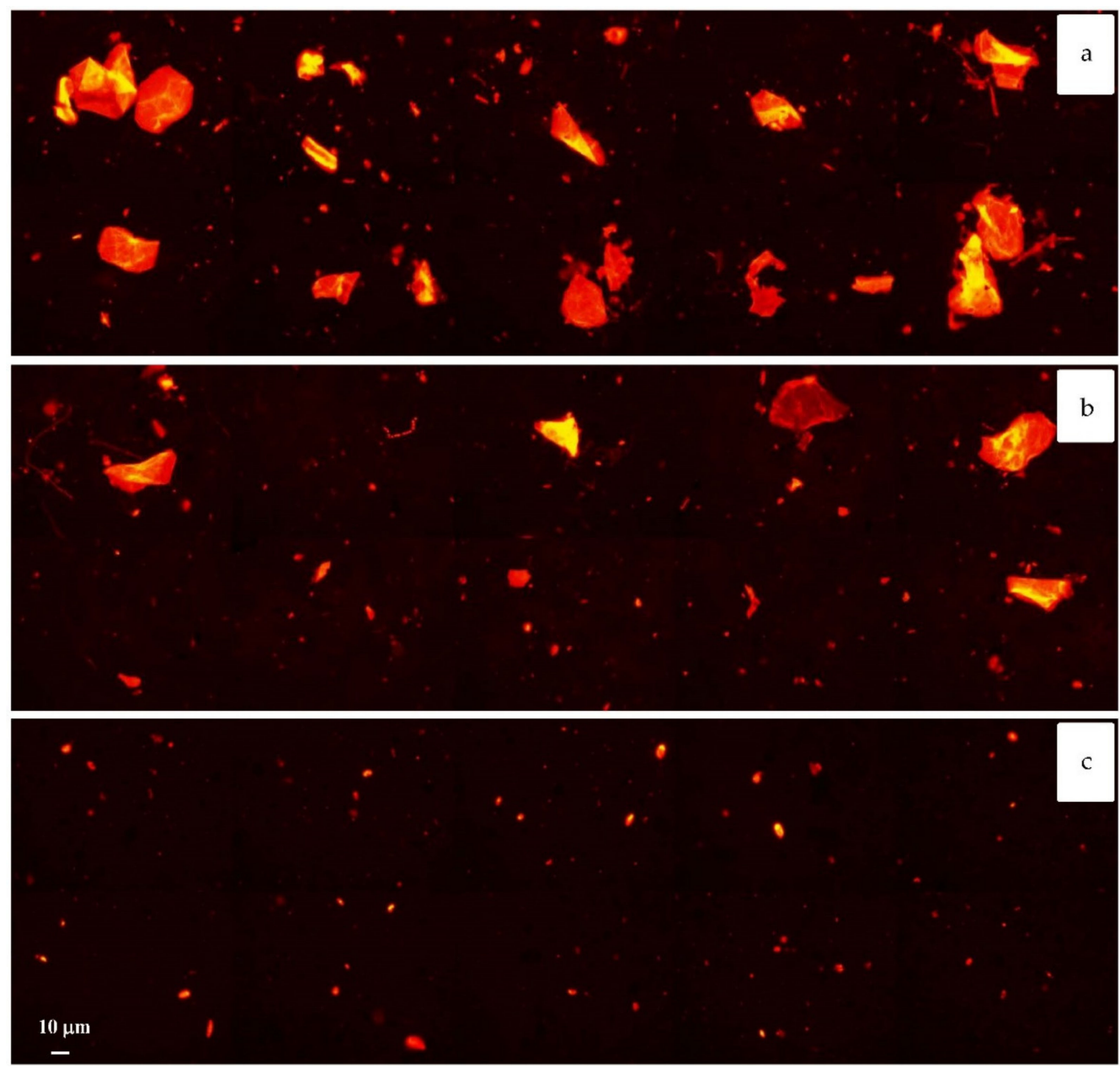

Figure 5. Microscope images (montage of ten fields) of the bioaerosol (fluorescent particles) inside classroom A4 during the day (a; 27-28/11), night (b; 27-28/11), and weekend (c; 2-3/12).

Typical microscope images referring to the samples collected on 13-14 November in the three indoor environments (LH, A4, CR) and outdoors are compared in Figure 6. The number of bioaerosol particles decreases from LH to A4, and from A4 to CR. In the first three images from the top, we can see many skin flake particles. These particles are not present outdoors (fourth image). In this image we can only recognize some fungal spores (particles of elongated shape, sometimes segmented, containing brighter circular areas corresponding to the nucleus) and other small circular bioparticles.

Concentration data for bioaerosol, $\mathrm{PM}_{10}$, and $\mathrm{OM}$ at the four investigated sites are reported in Table 1. For all three indoor sites, the variation over time of bioaerosol concentration was very similar to that observed in A4, i.e., much higher values during the day than at night, and even lower values over the weekend, a trend that was not observed for the outdoor site. The different bioaerosol concentrations among different periods and sites were plausibly linked to the classroom volume and the number of people inside, which varied according to the number of lessons provided and the number of students who attended them. The lack of detailed information about attendance did not allow us to verify if the bioaerosol concentration was proportional to the number of students. However, the data in Table 1 indicated that at the less crowded classroom CR $\left(11 \mathrm{~m}^{3}\right.$ per person) the concentration of bioaerosol was much lower than at $\mathrm{LH}$ and $\mathrm{A} 4\left(3.8\right.$ and $4.4 \mathrm{~m}^{3}$ per person, respectively). 

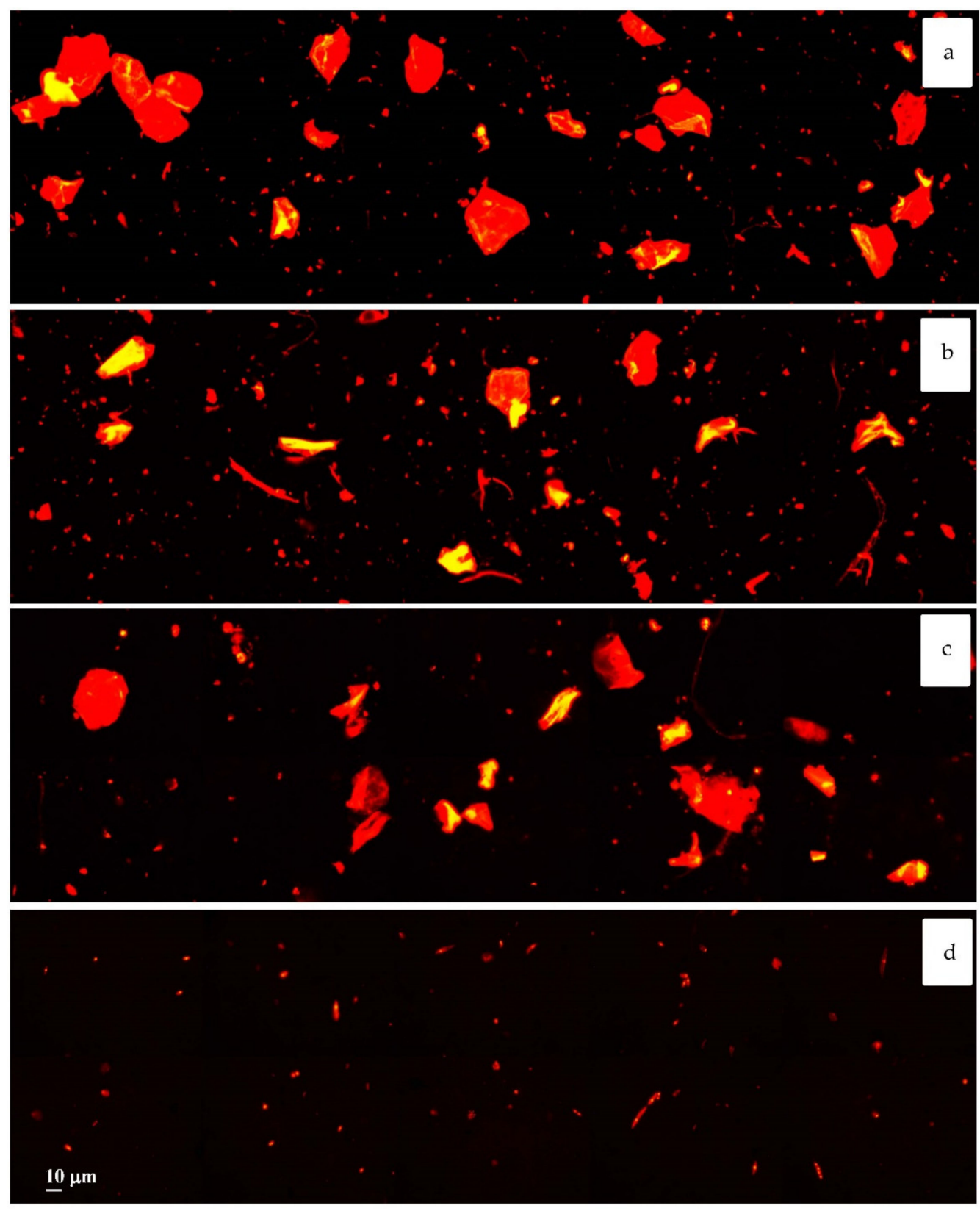

Figure 6. Microscope images (montage of ten fields) of the bioaerosol inside classrooms LH (lecture hall) (a), A4 (classroom) (b), CR (computer room) (c), and outdoors (d) on 13-14 November.

For $\mathrm{PM}_{10}, \mathrm{OM}$, and bioaerosol, we calculated the In/Out (I/O) ratio for the day, night, and weekend periods. For $\mathrm{PM}_{10}, \mathrm{I} / \mathrm{O}$ was $2.5 \pm 0.7$ during the day, $1.0 \pm 0.5$ during the night, and $0.6 \pm 0.1$ during the weekend. For $\mathrm{OM}, \mathrm{I} / \mathrm{O}$ values during the day were lower than those recorded for $\mathrm{PM}_{10}(1.3 \pm 0.3)$, while they were very similar during the night $(1.0 \pm 0.4)$ and the weekend $(0.6 \pm 0.05)$. This finding confirms the observation made for classroom A4 about the relevance of the infiltration from outside compared to the internal production of organic species. For bioaerosol, the ratios were $6.0 \pm 4.6$ for the day, and 3.6 \pm 3.0 for the night. During the weekend, I/O was 0.7 at both LH and CR. At A4, instead, the ratio during the weekend was 2.3 due to the unexpected presence of students during some hours on Saturday. Despite the higher data variability, I/O values much higher than one confirm, for all classrooms, the quantitative importance of the indoor source of bioaerosol due to people's presence. 
Table 1. Concentration $\left(\mu \mathrm{g} / \mathrm{m}^{3}\right)$ of bioaerosol, $\mathrm{PM}_{10}$ and $\mathrm{OM}$ detected in $\mathrm{LH}, \mathrm{A} 4, \mathrm{CR}$, and outdoors during the week 13-19 November.

\begin{tabular}{|c|c|c|c|c|}
\hline & & Bioaerosol & $\mathbf{P M}_{10}$ & OM \\
\hline 13-14/11 day & \multirow{5}{*}{ LH } & 14 & 54 & 23 \\
\hline 13-14/11 night & & 4.5 & 15 & 11 \\
\hline 15-16-17/11 day & & 9.9 & 51 & 14 \\
\hline $15-16-17 / 11$ night & & 0.94 & 16 & 7.8 \\
\hline 18-19/11 weekend & & 0.46 & 17 & 8.6 \\
\hline 13-14/11 day & \multirow{5}{*}{ A4 } & 5.2 & 80 & 27 \\
\hline 13-14/11 night & & 4.2 & 26 & 12 \\
\hline 15-16-17/11 day & & 9.0 & 78 & 16 \\
\hline $15-16-17 / 11$ night & & 3.3 & 23 & 9.6 \\
\hline 18-19/11 weekend & & 1.6 & 22 & 9.9 \\
\hline 13-14/11 day & \multirow{5}{*}{ CR } & 6.8 & 43 & 16 \\
\hline 13-14/11 night & & 0.66 & 8.5 & 6.7 \\
\hline 15-16-17/11 day & & 2.3 & 72 & 15 \\
\hline $15-16-17 / 11$ night & & 1.8 & 14 & 8.3 \\
\hline 18-19/11 weekend & & 0.46 & 15 & 9.8 \\
\hline 13-14/11 day & \multirow{5}{*}{ OUT } & 2.7 & 27 & 15 \\
\hline 13-14/11 night & & 0.59 & 14 & 8.0 \\
\hline 15-16-17/11 day & & 0.8 & 24 & 14 \\
\hline 15-16-17/11 night & & 1.1 & 22 & 12 \\
\hline 18-19/11 weekend & & 0.70 & 29 & 15 \\
\hline
\end{tabular}

To assess which bioaerosol particles were most responsible for these high I/O values, we studied the frequency distributions of the fluorescent particles in terms of individual mass. Figure 7 shows the bioparticles collected indoors, inside LH, and outdoors, clustered by six mass intervals, from $<2$ to $>100 \mathrm{pg}$ (frequency distribution and relative frequency distribution data are reported in Supplementary Materials, Table S2). At LH, the percentage of bioparticles belonging to each class was very similar during days and nights, in all cases, most of the particles (about 40-60\%) weighed less than $2 \mathrm{pg}$. During the weekend, however, the number of particles was more evenly distributed. Outdoors, the total number of bioparticles was much lower: 1277 versus 4053 (referring to the whole week and the examined filter sections). Moreover, the frequency distribution also varied; the number of particles was almost evenly distributed between $<2$ and $100 \mathrm{pg}$. These differences confirm that the bioparticles collected during workdays at the two sites belong to different populations.

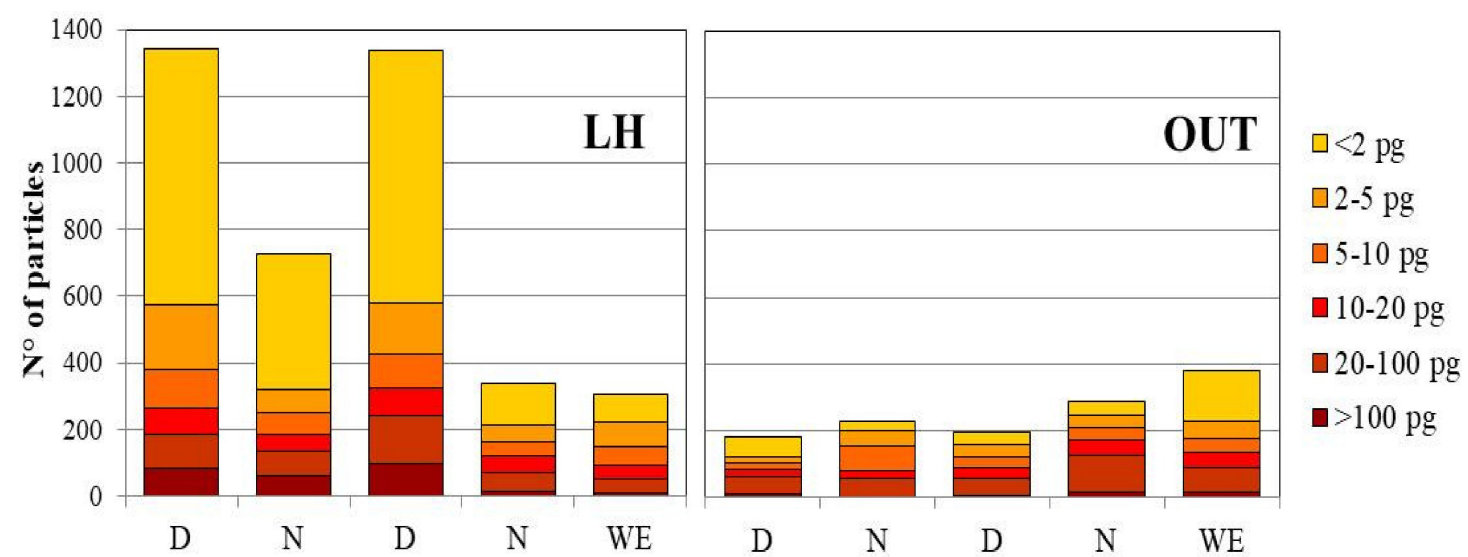

Figure 7. Frequency distribution of the number of bioparticles in six mass class ranges indoor (at LH) and outdoor during the days (D), nights (N), and weekend (WE) of the week 13-19 November. Sampling periods on Monday-Tuesday and Wednesday-Friday were been combined. 
We also calculated the total mass of bioparticles belonging to each group and, for each group, the average weight increase at LH with respect to outdoors (Figure 8 ). The data show that the weight increase of bioaerosol observed at LH during the day (and, to a lesser extent, the night) was mainly due to the largest particles (between 20 and $100 \mathrm{pg}$ ) and, above all, to those weighing more than $100 \mathrm{pg}$. On average, during the day indoors, particles heavier than $100 \mathrm{pg}$ were only $6 \%$, but they were responsible for $83 \%$ of the concentration increase of the bioaerosol mass with respect to outdoors. Their contribution justifies the high I/O values determined for bioaerosol and confirms the primary role of people in determining bioaerosol concentration in crowded indoor environments.

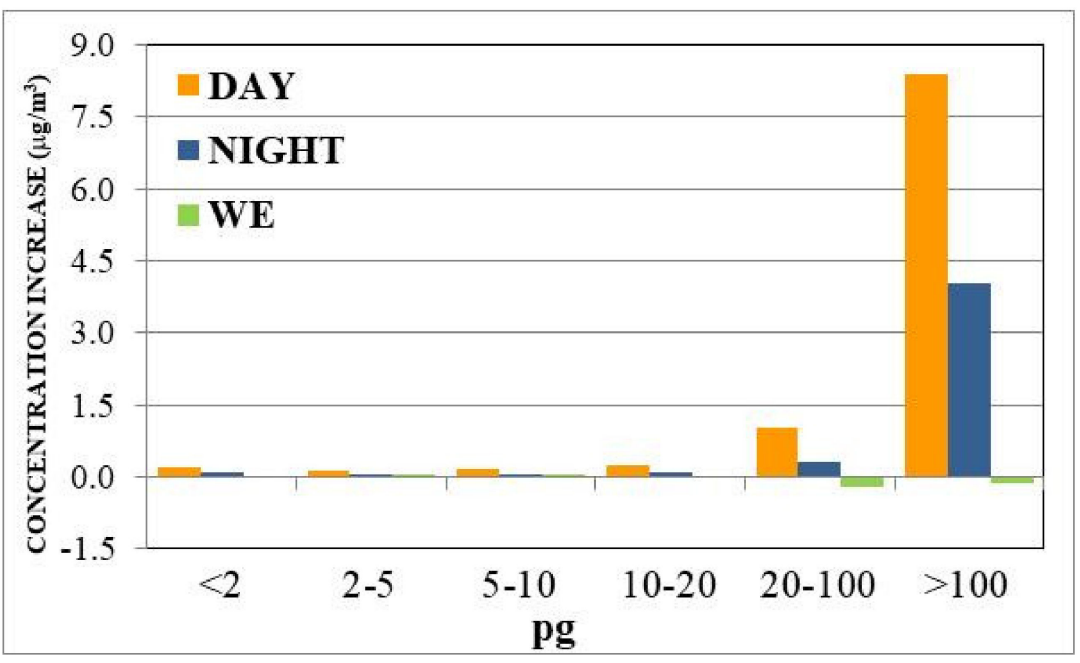

Figure 8. Bioaerosol increase at LH with respect to outdoors, expressed in mass concentration $\left(\mu \mathrm{g} / \mathrm{m}^{3}\right)$, during the week 13-19 November: distribution among ranges of individual bioparticles mass (in picograms).

The results of our study are in agreement with literature findings although, to our knowledge, the published papers concerning academic environments and schools only refer to specific bioaerosol types, and do not report information about total bioaerosol mass concentration. Although bioaerosol concentration is discussed in terms of $\mathrm{CFU} / \mathrm{m}^{3}$ (colony-forming units) [30,32,34,36,37], spores $/ \mathrm{m}^{3}$ [29], or concentration of biomarkers [31], the reported results converge in indicating that in indoor environments concentrations are higher than outdoors. Most of these papers also reported an increase in concentration during occupation.

In particular, our findings agree with the results of the study carried out in a $75 \mathrm{~m}^{3}$ experimental chamber by Bhangar et al. [47]. In this study, carried out using a UV-APS (laser-induced fluorescence-based sampling embodied in an ultraviolet aerodynamic particle sizer), it was reported that humans emit bioparticles, the emission increases when moving or walking, and clothing and its frictional interaction with skin is a primary source of coarse bioaerosol. Occupant emission rate was estimated to average $0.9 \pm 0.3$ million particles/person-h.

\section{Conclusions}

The examined indoor university environments were characterized by a high bioaerosol concentration, particularly during lesson hours, when bioparticles contributed $30 \%$ to the organics and $10 \%$ to the total $\mathrm{PM}_{10}$ mass concentration. During the night periods and the weekends, when the classrooms were empty, bioaerosol concentration decreased significantly, indicating a primary role of occupants. The microscope analysis showed that during the day periods the samples were characterized by many large and light particles, identified as skin flakes. Particles heavier than $100 \mathrm{pg}$ were mostly responsible for the indoor increase in bioaerosol concentration during lesson hours pointing, again, to the 
central role of occupants. The quantitative determination of bioaerosol by propidium iodide staining and observation by optical microscopy were also confirmed as suitable for the observation and quantitative determination of total bioaerosol particles in crowded indoor environments.

The role of people in determining high indoor/outdoor ratios (up to 12) in crowded environments constitutes a step forward in identifying the indoor sources of PM. This study adds quantitative information to the consolidating evidence that human occupancy contributes meaningfully to indoor bioaerosol levels, and raises questions about the mechanisms for the spread of contagious disease in crowded conditions.

Our observations cannot differentiate between emissions from the body envelope (skin, hair, and clothing) and re-suspension from the floor and other surfaces. This distinction, of interest for designing control measures and evaluating potential health impacts, will be the subject of future research. There is also a need to elucidate the proportionality between the number of occupants and bioaerosol concentration, and to assess the role of different activity levels.

Supplementary Materials: The following are available online at https://www.mdpi.com/2071-1 050/13/3/1149/s1, Table S1: Indoor concentration of bioaerosol, $\mathrm{PM}_{10}$ and organic matter (OM) in classroom A4 during the study period, Table S2: Frequency distribution and relative frequency distribution of bioaerosol indoors (Lecture Hall) and outdoors during the days, nights and weekend of the week 13-19 November: number and percentage of particles belonging to each mass cluster. Sampling periods on Monday-Tuesday and Wednesday-Friday have been combined.

Author Contributions: Conceptualisation, C.P.; Methodology, F.M. and C.P.; Validation, F.M.; Formal Analysis, F.M. and C.P.; Investigation, F.M.; Resources, F.M.; Data Curation, F.M.; Writing-Original Draft Preparation, C.P.; Writing-Review \& Editing, C.P.; Visualisation, C.P.; Supervision, C.P.; Project Administration, C.P.; Funding Acquisition, C.P. All authors have read and agreed to the published version of the manuscript.

Funding: This research was funded by INAIL in the frame of its scientific research programs (2016-2018).

Institutional Review Board Statement: Not applicable.

Informed Consent Statement: Not applicable.

Data Availability Statement: Data is contained within the article or supplementary material.

Acknowledgments: The coordinator of the VIEPI project, A. Pelliccioni (INAIL), is gratefully acknowledged. The Authors are grateful to the CNIS (Research Center on Nanotechnology Applied to Engineering) of the Sapienza University of Rome and especially to. F. Mura for his precious assistance in SEM analyses. The Authors are also indebted to T. Sargolini for the analyses of organic carbon and to M. Catrambone, S. Dalla Torre, G. Esposito, M. Giusto, S. Pareti, E. Rantica, T. Sargolini and L. Tofful for their invaluable contribution to sampling and analytical activities in the VIEPI project. D. Greco and M. Segreto are gratefully acknowledged for their contribution to the management of the project.

Conflicts of Interest: The authors declare no conflict of interest.

\section{References}

1. Pelliccioni, A.; Monti, P.; Cattani, G.; Boccuni, F.; Cacciani, M.; Canepari, S.; Capone, P.; Catrambone, M.; Cusano, M.; D’Ovidio, M.C.; et al. Integrated evaluation of indoor particulate exposure: The VIEPI project. Sustainability 2020, 12, 9758. [CrossRef]

2. Merriam-Webster.com Medical Dictionary, Merriam-Webster. Available online: https://www.merriam-webster.com/medical/ bioaerosol (accessed on 5 January 2021).

3. Womiloju, T.O.; Miller, J.D.; Mayer, P.M.; Brook, J.R. Methods to determine the biological composition of particulate matter collected from outdoor air. Atmos. Environ. 2003, 37, 4335-4344. [CrossRef]

4. Li, Q.; Dasgupta, P.K.; Temkin, H.; Crawford, M.H.; Fischer, A.J.; Allerman, A.A.; Bogart, K.H.A.; Lee, S.R. Mid-ultraviolet light-emitting diode detects dipicolinic acid. Appl. Spectrosc. 2004, 58, 1360-1363. [CrossRef] [PubMed]

5. Buiarelli, F.; Canepari, S.; Di Filippo, P.; Perrino, C.; Pomata, D.; Riccardi, C.; Speziale, R. Extraction and analysis of fungal spore biomarkers in atmospheric bioaerosol by HPLC-MS-MS and GC-MS. Talanta 2013, 105, 142-151. [CrossRef] 
6. $\quad$ Buiarelli, F.; Riccardi, C.; Uccelletti, D.; Pomata, D.; Sonego, E.; Bruni, E.; Marcovecchio, F.; Simonetti, G.; Di Filippo, P.; Perrino, C. Determination of the main bioaerosol components using chemical markers by liquid chromatography-tandem mass spectrometry. Microchem. J. 2019, 149, 103974. [CrossRef]

7. Di Filippo, P.; Pomata, D.; Riccardi, C.; Buiarelli, F.; Uccelletti, D.; Zanni, E. Muramic and dipicolinic acids in atmospheric particulate matter as biomarkers of bacteria and bacterial spores. Anal. Bioanal. Chem. 2017, 409, 1657-1666. [CrossRef]

8. An, H.R.; Mainelis, G.; While, L. Development and calibration of real-time PCR for quantification of airborne microorganisms in air samples. Atmos. Environ. 2006, 40, 7924-7939. [CrossRef]

9. Blais-Lecours, P.; Perrott, P.; Cuchaine, C. Non-culturable bioaerosols in indoor settings: Impact on health and molecular approach for detection. Atmos. Environ. 2015, 110, 45-53. [CrossRef]

10. Huffman, J.A.; Sinha, B.; Garland, R.M.; Snee-Pollmann, A.; Gunthe, S.S.; Artaxo, P.; Martin, S.T.; Andreae, M.; Poschl, U. Size distribution and temporal variations of biological aerosol particles in the Amazon rainforest characterised by microscopy and real-time UV-APS fluorescence techniques during AMAZE-08. Atmos. Chem. Phys. 2012, 12, 11997-12019. [CrossRef]

11. Toprak, E.; Schnaiter, M. Fluorescent biological aerosol particels measured with the waveband integrated bioaerosol sensor WIBS-4: Laboratory tests combined with a one year field study. Atmos. Chem. Phys. 2013, 13, 225-243. [CrossRef]

12. Fennelly, M.J.; Sewell, G.; Prentice, M.B.; O'Connor, D.J.; Sodeau, J.R. The use of real-time fluorescence instrumentation to monitor ambient primary biological aerosol particles (PBAP). Atmosphere 2018, 9, 1. [CrossRef]

13. Perrino, C.; Marcovecchio, F. A new method for assessing the contribution of Primary Biological Atmospheric Particles to the mass concentration of the atmospheric aerosol. Environ. Int. 2016, 87, 108-115. [CrossRef] [PubMed]

14. Chen, L.W.A.; Zhang, M.; Liu, T.; Fortier, K.; Chow, J.C.; Alonzo, F.; Kolberg, R.; Cao, J.; Lin, G.; Tanviben, Y.P.; et al. Evaluation of epifluorescence methods for quantifying bioaerosols in fine and coarse particulate air pollution. Atmos. Environ. 2019, 213, 620-628. [CrossRef]

15. Dechow, M.; Sohn, H.; Steinhanses, J. Concentrations of selected contaminants in cabin air of airbus aircrafts. Chemosphere 1997, 35, 21-31. [CrossRef]

16. Chen, Q.; Hildemann, L.M. The effects of human activities on exposure to particulate matter and bioaerosols in residential homes. Environ. Sci. Technol. 2009, 43, 4641-4646. [CrossRef]

17. Pereira, M.L.; Knibbs, L.D.; He, C.; Grzybowski, P.; Johnson, G.R.; Huffman, J.A.; Bell, S.C.; Wainwright, C.E.; Matte, D.L.; Dominski, F.H.; et al. Sources and dynamics of fluorescent particles in hospitals. Indoor Air 2017, 27, 988-1000. [CrossRef]

18. Bragoszewska, E. Exposure to Bacterial and Fungal Aerosols: Microorganism Indices in A Waste-Sorting Plant in Poland. Int. J. Environ. Res. Public Health 2019, 16, 3308. [CrossRef]

19. Gaidajis, G.; Angelakoglou, K. Indoor air quality in university classrooms and relative environment in terms of mass concentrations of particulate matter. J. Environ. Sci. Health Part A 2009, 44, 1227-1232. [CrossRef]

20. Stabile, L.; Buonanno, G.; Avino, P.; Fuoco, F.C. Dimensional and chemical characterisation of airborne particles in schools: Respiratory effects in children. Aerosol Air Qual. Res. 2013, 13, 887-900. [CrossRef]

21. Viana, M.; Rivas, I.; Querol, X.; Alastuey, A.; Sunyer, J.; Álvarez-Pedrerol, M.; Bouso, L.; Sioutas, C. Indoor/outdoor relationships and mass closure of quasi-ultrafine, accumulation and coarse particles in Barcelona schools. Atmos. Chem. Phys. 2014, 14, 4459-4472. [CrossRef]

22. Fuoco, F.C.; Stabile, L.; Buonanno, G.; Trassiera, C.V.; Massimo, A.; Russi, A.; Mazaheri, M.; Morawska, L.; Andrade, A. Indoor air quality in naturally ventilated Italian classrooms. Atmosphere 2015, 6, 1652-1675. [CrossRef]

23. Tofful, L.; Perrino, C. Chemical composition of indoor and outdoor $\mathrm{PM}_{2.5}$ in three schools in the city of Rome. Atmosphere 2015, 6, 1422-1443. [CrossRef]

24. Pallarés, S.; Gómez, E.; Martínez, A.; Jordán, M.M. The relationship between indoor and outdoor levels of PM10 and its chemical composition at schools in a coastal region in Spain. Heliyon 2019, 5, e02270. [CrossRef] [PubMed]

25. Ruggieri, S.; Longo, V.; Perrino, C.; Canepari, S.; Drago, G.; L’Abbate, L.; Balzan, M.; Cuttitta, G.; Scaccianoce, G.; Minardi, R.; et al. Indoor air quality in schools of a highly polluted South Mediterranean area. Indoor Air 2019, 29, 276-290. [CrossRef] [PubMed]

26. Sánchez-Soberón, F.; Rovira, J.; Sierra, J.; Mari, M.; Domingo, J.L.; Schuhmacher, M. Seasonal characterisation and dosimetryassisted risk assessment of indoor particulate matter $\left(\mathrm{PM}_{10-2.5}, \mathrm{PM}_{2.5-0.25}\right.$, and $\left.\mathrm{PM}_{0.25}\right)$ collected in different schools. Environ. Res. 2019, 175, 287-296.

27. Bragoszewska, E.; Biedroń, I.; Mainka, A. Microbiological Air Quality in a Highschool Gym Located in an Urban Area of Southern Poland-Preliminary Research. Atmosphere 2020, 11, 797. [CrossRef]

28. Martins, V.; Faria, T.; Diapouli, E.; Manousakas, M.I.; Eleftheriadis, K.; Viana, M.; Almeida, S.M. Relationship between indoor and outdoor size-fractionated particulate matter in urban microenvironments: Levels, chemical composition and sources. Environ. Res. 2020, 183, 109203. [CrossRef]

29. Toivola, M.; Alm, S.; Reponen, T.; Kolari, S.; Nevalainen, A. Personal exposures and microenvironmental concentrations of particles and bioaerosols. J. Environ. Monit. 2002, 4, 166-174. [CrossRef]

30. Bartlett, K.H.; Kennedy, S.M.; Brauer, M.; van Netten, C.; Dill, B. Evaluation and determinants of airborne bacterial concentrations in school classrooms. J. Occup. Environ. Hyg. 2004, 1, 639-647. [CrossRef]

31. Fox, A.; Harley, W.; Feigley, C.; Salzberg, D.; Toole, C.; Sebastian, A.; Larsson, L. Large particles are responsible for elevated bacterial marker levels in school air upon occupation. J. Environ. Monitor. 2005, 7, 450-456. [CrossRef] 
32. Brandl, H.; von Däniken, A.; Hitz, C.; Krebs, W. Short-term dynamic patterns of bioaerosol generation and displacement in an indoor environment. Aerobiologia 2008, 24, 203-209. [CrossRef]

33. Mandal, J.; Brandl, H. Bioaerosols in indoor environment-a review with special reference to residential and occupational locations. Open Environ. Biol. Monit. J. 2011, 4, 83-96.

34. Grisoli, P.; Rodolfi, M.; Chiara, T.; Zonta, L.A.; Dacarro, C. Evaluation of microbiological air quality and of microclimate in university classrooms. Environ. Monit. Assess. 2012, 184, 4171-4180. [CrossRef] [PubMed]

35. Canha, N.; Almeida, S.M.; do Carmo Freitas, M.; Wolterbeek, H.T. Assessment of bioaerosols in urban and rural primary schools using passive and active sampling methodologies. Arch. Environ. Prot. 2015, 41, 11-22. [CrossRef]

36. Madureira, J.; Paciência, I.; Pereira, C.; Teixeira, J.P.; Fernandes, E.D.O. Indoor air quality in Portuguese schools: Levels and sources of pollutants. Indoor Air 2016, 26, 526-537. [CrossRef]

37. Bragoszewska, E.; Mainka, A.; Pastuszka, J.S.; Lizończyk, K.; Desta, Y.G. Assessment of bacterial aerosol in a preschool, primary school and high school in Poland. Atmosphere 2018, 9, 87. [CrossRef]

38. Madureira, J.; Aguiar, L.; Pereira, C.; Mendes, A.; Querido, M.M.; Neves, P.; Teixeira, J.P. Indoor exposure to bioaerosol particles: Levels and implications for inhalation dose rates in schoolchildren. Air Qual. Atmos. Health 2018, 11, 955-964. [CrossRef]

39. Hospodsky, D.; Qian, J.; Nazaroff, W.W.; Yamamoto, N.; Bibby, K.; Rismani-Yazdi, H.; Peccia, J. Human occupancy as a source of indoor airborne bacteria. PLoS ONE 2012, 7, e34867. [CrossRef]

40. Marcovecchio, F.; Perrino, C. Contribution of Primary Biological Aerosol Particles to airborne particulate matter in indoor and outdoor environments. Chemosphere 2021, 264, 128510. [CrossRef]

41. Pongracic, J.A.; O'Connor, G.T.; Muilenberg, M.L.; Vaughn, B.; Gold, D.R.; Kattan, M.; Morgan, W.J.; Gruchalla, R.S.; Smartt, E.; Mitchell, H.E. Differential effects of outdoor versus indoor fungal spores on asthma morbidity in inner-city children. J. Allergy Clin. Immun. 2010, 125, 593-599. [CrossRef]

42. Laumbach, R.J.; Kipen, H.M. Bioaerosols and sick building syndrome: Particles, inflammation, and allergy. Curr. Opin. Allergy Clin. Immunol. 2005, 5, 135-139. [CrossRef] [PubMed]

43. Mackintosh, C.A.; Lidwell, O.M.; Towers, A.G.; Marples, R.R. The dimensions of skin fragments dispersed into the air during activity. Epidemiol. Infect. 1978, 81, 471-480. [CrossRef] [PubMed]

44. Cummings, B.E.; Waring, M.S. Predicting the importance of oxidative aging on indoor organic aerosol concentrations using the two-dimensional volatility basis set (2D-VBS). Indoor Air 2019, 29, 616-629. [CrossRef] [PubMed]

45. Turpin, B.J.; Lim, H.J. Species contributions to $\mathrm{PM}_{2.5}$ mass concentrations: Revisiting common assumptions for estimating organic mass. Aerosol Sci. Technol. 2001, 35, 602-610. [CrossRef]

46. Reff, A.; Turpin, B.J.; Offenberg, J.H.; Weisel, C.P.; Zhang, J.; Morandi, M.; Stock, T.; Colome, S.; Winer, A. A functional group characterisation of organic $\mathrm{PM}_{2.5}$ exposure: Results from the RIOPA study. Atmos. Environ. 2007, 41, 4585-4598. [CrossRef]

47. Bhangar, S.; Adams, R.I.; Pasut, W.; Huffman, J.A.; Arens, E.A.; Taylor, J.W.; Bruns, T.D.; Nazaroff, W.W. Chamber bioaerosol study: Human emissions of size-resolved fluorescent biological aerosol particles. Indoor Air 2016, 26, 193-206. [CrossRef] 